NATIONAL LABORATORY

\title{
RADIATION DETECTION FOR ACTIVE INTERROGATION OF HEU
}

\author{
J. T. Mihalczo
}

UT-BATTELLE 


\section{DOCUMENT AVAILABILITY}

Reports produced after January 1, 1996, are generally available free via the U.S. Department of Energy (DOE) Information Bridge.

Web site http://www.osti.gov/bridge

Reports produced before January 1, 1996, may be purchased by members of the public from the following source.

National Technical Information Service

5285 Port Royal Road

Springfield, VA 22161

Telephone 703-605-6000 (1-800-553-6847)

TDD 703-487-4639

Fax 703-605-6900

E-mail info@ntis.fedworld.gov

Web site http://www.ntis.gov/support/ordernowabout.htm

Reports are available to DOE employees, DOE contractors, Energy Technology Data Exchange (ETDE) representatives, and International Nuclear Information System (INIS) representatives from the following source.

Office of Scientific and Technical Information

P.O. Box 62

Oak Ridge, TN 37831

Telephone 865-576-8401

Fax 865-576-5728

E-mail reports@adonis.osti.gov

Web site http://www.osti.gov/contact.html

This report was prepared as an account of work sponsored by an agency of the United States Government. Neither the United States government nor any agency thereof, nor any of their employees, makes any warranty, express or implied, or assumes any legal liability or responsibility for the accuracy, completeness, or usefulness of any information, apparatus, product, or process disclosed, or represents that its use would not infringe privately owned rights. Reference herein to any specific commercial product, process, or service by trade name, trademark, manufacturer, or otherwise, does not necessarily constitute or imply its endorsement, recommendation, or favoring by the United States Government or any agency thereof. The views and opinions of authors expressed herein do not necessarily state or reflect those of the United States Government or any agency thereof. 
ORNL/TM-2004/302

Nuclear Science and Technology Division

\title{
RADIATION DETECTION FOR ACTIVE INTERROGATION OF HEU
}

\author{
J. T. Mihalczo
}

Date published: December 2004

Prepared by

OAK RIDGE NATIONAL LABORATORY

Oak Ridge, Tennessee 37831-6285

managed by

UT-BATTELLE, LLC

for the

U.S. DEPARTMENT OF ENERGY

under contract DE-AC05-00OR22725 



\section{CONTENTS}

Page

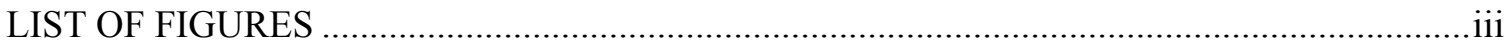

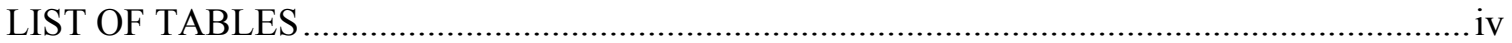

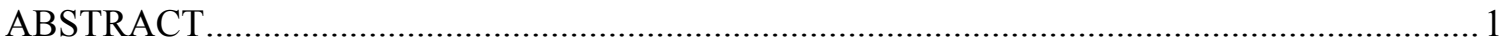

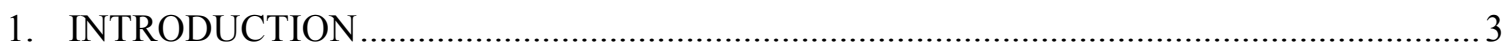

$1.1 \quad$ NEUTRONS AND GAMMA RAYS FROM FISSION …........................................ 3

1.2 TIME DEPENDENCE OF DELAYED NEUTRONS ….......................................... 3

1.3 TIME DEPENDENCE OF DELAYED GAMMA RAYS ........................................ 4

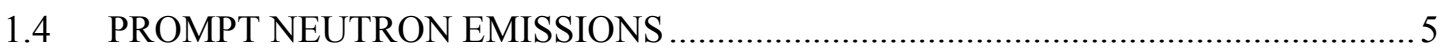

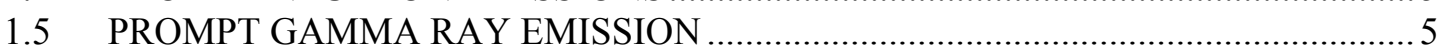

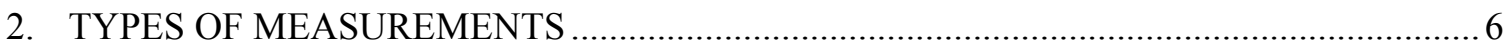

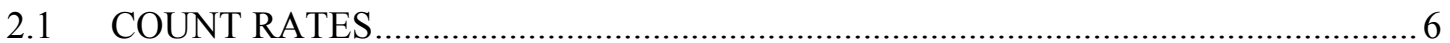

2.2 PROMPT MULTIPLET DISTRIBUTIONS AND MULTIPLICITIES …..................... 6

2.3 TIME CORRELATION MEASUREMENTS BETWEEN DETECTORS................... 8

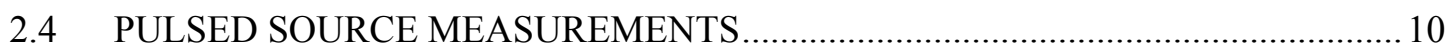

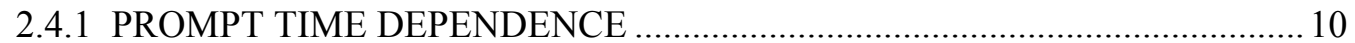

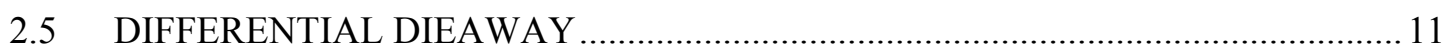

2.5.1 DELAYED NEUTRON COUNT RATE BETWEEN PULSES .........................11

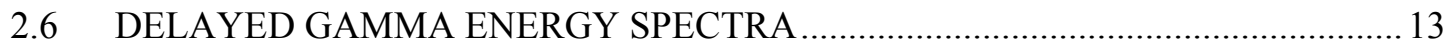

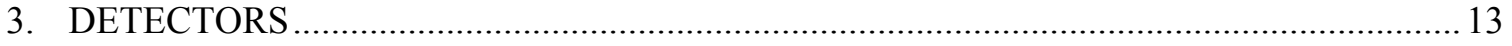

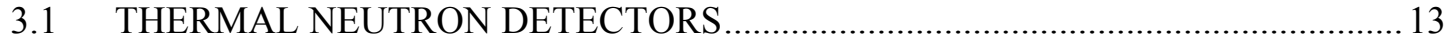

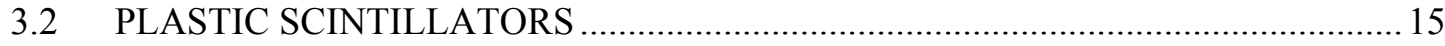

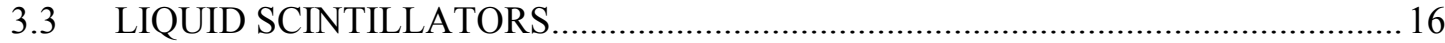

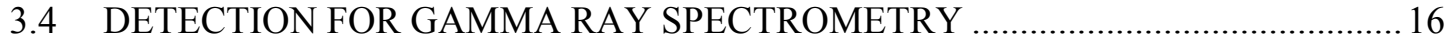

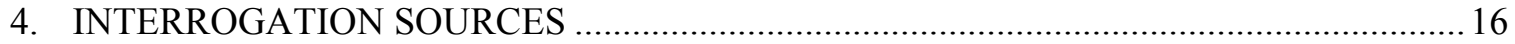

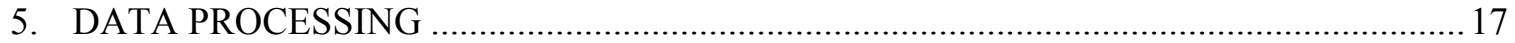

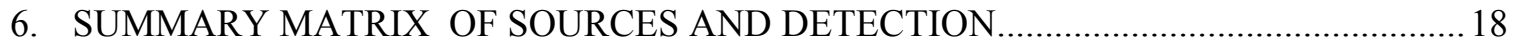

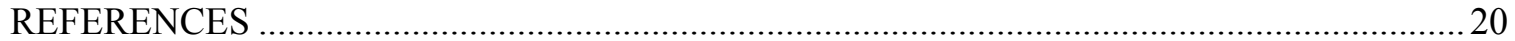




\section{LIST OF FIGURES}

\section{Figure}

1. Comparison between ORNL irradiation measurements and delayed gamma decay model predictions

2. Thermal neutron induced ${ }^{235} \mathrm{U}$ multiplicity of prompt gamma rays from the negative binomial distribution of Valentine

3. Number of times $\mathrm{n}$ pulses occur in a $512 \mathrm{nsec}$ window from plastic scintillators from NMIS $9 \sim 8.5$ minute measurement in 1998) for a HEW (93.2 $\left.{ }^{235} \mathrm{U}\right) 18.75 \mathrm{~kg}$ meUal casting

4. Time distribution of coincidences between two plastic scintillation detectors for an annular $18.75 \mathrm{~kg}$ HEU (93.2 $\left.{ }^{235} \mathrm{U}\right)$ metal storage casting.

5. Photograph of the plastic scintillator arrangement and a $4 \mathrm{~kg}$ Pu Metal $\left(1.77 \%{ }^{240} \mathrm{Pu}\right)$

spherical shell with one detector removed ................................................................. 9

6. Time distribution of coincidences between two plastic scintillation detectors for a 3.3 $\mathrm{Kg} \mathrm{Pu}$ Metal $\left(1.77\right.$ wt of $\left.{ }^{240} \mathrm{Pu}\right)$ spherical shell

7. Time distribution of counts after $30 \mathrm{nsec}$ accelerator pulses for an 11-in.-diam, 2.5-in.-high HEU cylinder. 10

8. Time distribution of counts in a plastic scintillator after $\mathrm{Cf}$ fission for an annular $18.75 \mathrm{~kg}$ HEU metal storage casting.

9. Typical differential dieaway data from a package monitor at LANL ........................ 12

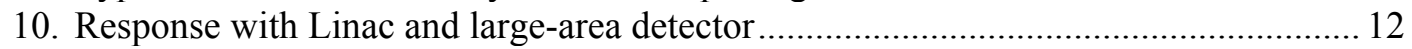

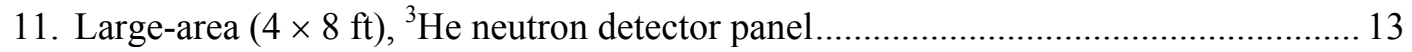

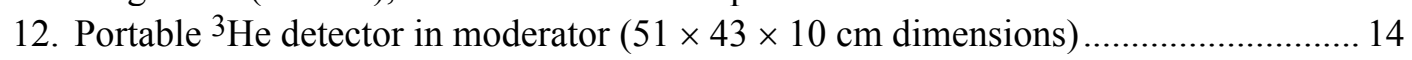

13. INL's ${ }^{3} \mathrm{He}$ proportional counter for pulsed LINAC photo fission measurements........ 14

14. Large panels of ${ }^{6} \mathrm{Li}$ glass fiber thermal neutron detectors........................................... 15

15. Photograph of a $1 \times 1$ meter plastic scintillator in testing at ORNL ............................. 16 


\title{
LIST OF TABLES
}

Table

Page

$1 \quad$ Delayed neutron data of Keepin, Wimmett, and Zeigler..................................... 4

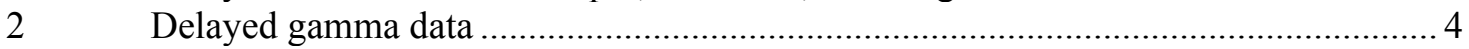

3 Distribution of prompt neutron numbers for thermal fission of ${ }^{235} \mathrm{U}$......................... 5

$4 \quad$ Matrix of interrogating sources and potenial measurements .................................... 19

\section{RADIATION DETECTION FOR ACTIVE} INTERROGATION OF HEU

\section{J. T. Mihalczo}

\begin{abstract}
This report briefly describes the neutrons and gamma rays emitted by active interrogation of HEU, briefly discusses measurement methods, briefly discusses sources and detectors relevant to detection of shielded HEU in Sealand containers, and lists the measurement possibilities for the various sources. All but one of the measurement methods detect radiation emitted by induced fission in the HEU; the exception utilizes nuclear resonance fluorescence. The brief descriptions are supplemented by references. This report presents some active interrogation possibilities but the status of understanding is not advanced enough to select particular methods. Additional research is needed to evaluate these possibilities.
\end{abstract}




\title{
RADIATION DETECTION FOR ACTIVE INTERROGATION OF HEU
}

\author{
J. T. Mihalczo
}

\section{INTRODUCTION}

This report briefly describes the neutrons and gamma rays emitted in fission, briefly discusses measurement methods, briefly discusses sources and detectors relevant to detection of shielded highly enriched uranium (HEU) in Sealand containers, and lists the measurement possibilities for the various sources. All but one of the measurement methods detect radiation emitted by induced fission in the HEU; the exception utilizes nuclear resonsance fluorescence. It is not meant to be a comprehensive description with very many details. The brief descriptions are supplemented by references. This report presents some active interrogation possibilities, but the status of understanding is such that particular method can not be selected without further research.

\subsection{NEUTRONS AND GAMMA RAYS FROM FISSION}

The fission process produces radiation that can be detected to indicate the presence of fissile material. Active interrogation with either photons or neutrons induces fission in the shielded HEU and a variety of radiation is produced. For the purpose of detection of fissile material, only gamma rays and neutrons are discussed in this report along with their time dependent emission characteristics. Neutrons and gamma rays that are emitted promptly $\left(10^{-14} \mathrm{sec}\right)$ are referred to as prompt emissions, while neutrons and gamma rays that are emitted after a fission event are referred to as delayed. For example, there are on average on average $\sim 2.5$ prompt neutrons emitted in ${ }^{235} \mathrm{U}$ fission and 0.016 delayed neutrons. For gamma rays there are $\sim 7$ prompt, and $\sim 7$ delayed gamma rays emitted per ${ }^{235} \mathrm{U}$ fission. However, each fission of ${ }^{235} \mathrm{U}$ emits different numbers of prompt neutrons (up to 6) and gamma rays (up to 20). These fluctuation distributions for prompt neutrons and prompt gamma rays are known. The fluctuations in the numbers of prompt emissions result in deviations from the Poisson statistics when measuring the number of particles emitted within a time interval. These deviations can indicate the presence of fissile material since fission produces coincident counts with higher multiplets. ${ }^{1}$ Further fissions are induced by both delayed and prompt neutrons through fission chain multiplication processes. For metallic HEU, the delayed neutrons have a higher probability for inducing fission than the prompt neutrons since they have lower energy and higher fission cross section. However, they are much less in number (factor of $\sim 150$ ). The time dependence of fission chain multiplication processes has been measured by a variety of methods. ${ }^{2,3}$ The number of delayed neutrons and gamma rays is proportional to the number of prompt neutrons. The ratio of delayed neutron emissions to prompt emissions is fixed and does not depend on the multiplication, although the total number does.

\subsection{TIME DEPENDENCE OF DELAYED NEUTRONS}

A wide variety of measurements of the time dependence of delayed neutron emission have been performed. Data from the original measurements of Keepin, Wimmett, and Zeigler ${ }^{4}$ are given in the following Table 1, where the time dependence has been represented by 6 delayed neutron groups with their relative yields and exponential decay constants. 
Table 1. Delayed neutron data of Keepin, Wimmett, and Zeigler

\begin{tabular}{ccc}
\hline Group & Relative yield & Decay constant $\left(\mathbf{s e c}^{\mathbf{- 1}}\right)$ \\
\hline 1 & 0.038 & 0.0127 \\
2 & 0.213 & 0.0317 \\
3 & 0.188 & 0.115 \\
4 & 0.407 & 0.311 \\
5 & 0.128 & 1.40 \\
6 & 0.026 & 3.87 \\
\hline
\end{tabular}

\subsection{TIME DEPENDENCE OF DELAYED GAMMA RAYS}

The time dependence of delayed gamma rays with energies above $300 \mathrm{keV}$ has been measured at ORNL by March-Leuba, et al. ${ }^{5}$ The measured delayed emission data have been fitted to a five-group model to represent the decay. This model includes a 300-keV energydiscrimination threshold that is accounted for in the overall detector efficiency. The detectors for these measurements were $6 \times 6 \times 2$-in.-thick BiGeO scintillators. The parameters of the five-group model are summarized in Table 4. Delayed gamma data, and a sample measurement is shown in Fig. 1. The parameters in Table 2 correspond to a best fit to the decay gamma data following a fission event, so that

$$
n_{\gamma}(\tau)=\sum_{1}^{5} \alpha_{i} e^{-\lambda_{i} \tau},
$$

where $n_{\gamma}(\tau)$ represents the average number of photons per second following a fission event, $\alpha_{i}$ is the group yield constant, which is related to the group precursor fraction, $\beta_{\mathrm{i}}$, as $\alpha_{\mathrm{i}}=\lambda_{\mathrm{i}} \times \beta_{\mathrm{i}}$. Figure 1 shows the results of applying the delayed gamma emission model to measured data obtained by irradiating a ${ }^{235} \mathrm{U}$ fission

Table 2. Delayed gamma data chamber for 60 and 600 seconds and measuring the decay gammas. As seen in Fig. 1, the delayed gamma emission model predicts the measured data accurately up to 500 seconds following the fission event. This decay model also benchmarks well against the impulse-response data published in the literature.

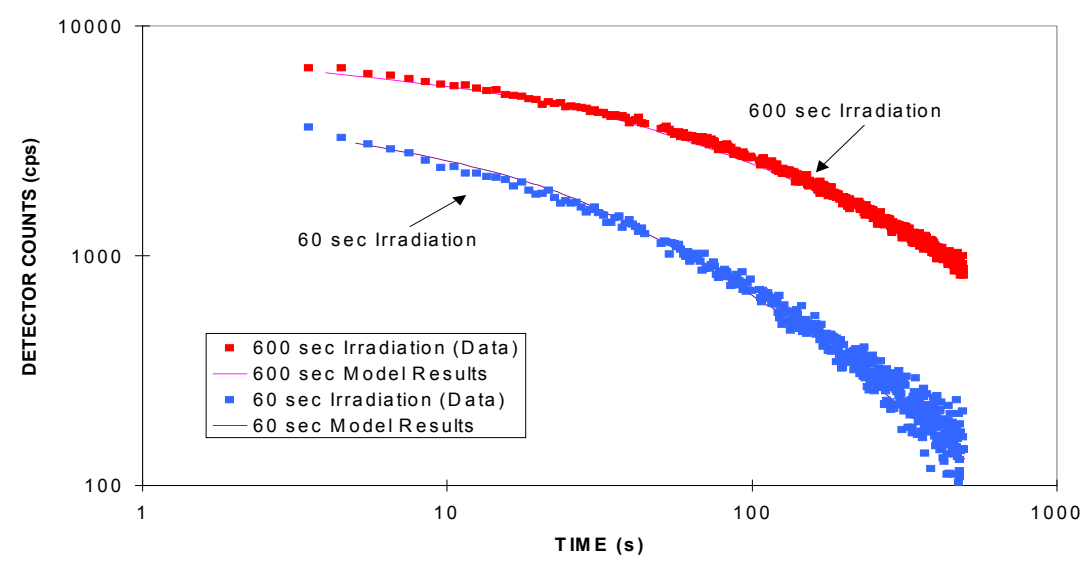

Fig. 1. Comparison between ORNL irradiation measurements and delayed gamma decay model predictions. 


\subsection{PROMPT NEUTRON EMISSIONS}

The distribution of the number of neutrons for ${ }^{235} U$ fission induced by thermal neutrons is given in Table $3{ }^{6}$ In some fissions, there are no neutrons emitted and in some fissions up to 6 . This distribution depends on the energy of the neutron inducing fission. More prompt neutrons are produced the higher the neutron energy inducing fission.

Table 3. Distribution of prompt neutron numbers for thermal fission of ${ }^{235} \mathrm{U}$

\begin{tabular}{cc}
\hline Number of neutrons & Fraction of emissions \\
\hline 0 & 0.0313 \\
1 & 0.1729 \\
2 & 0.3336 \\
3 & 0.3078 \\
4 & 0.1232 \\
5 & 0.0275 \\
6 & 0.0038 \\
\hline
\end{tabular}

\subsection{PROMPT GAMMA RAY EMISSION}

There is much less measured data for prompt gamma ray emission numbers. Measurements were performed by Brunson ${ }^{7}$ for ${ }^{252} \mathrm{Cf}$, a spontaneously fissioning isotope, and theoretical estimates of the distribution are given by Valentine. ${ }^{8}$ Typical distributions of gamma ray multiplicities from Ref. 8 for ${ }^{235} \mathrm{U}$ are plotted in Fig. 2 where the highest gamma multiplet is 20 and the average is $\sim 7$.

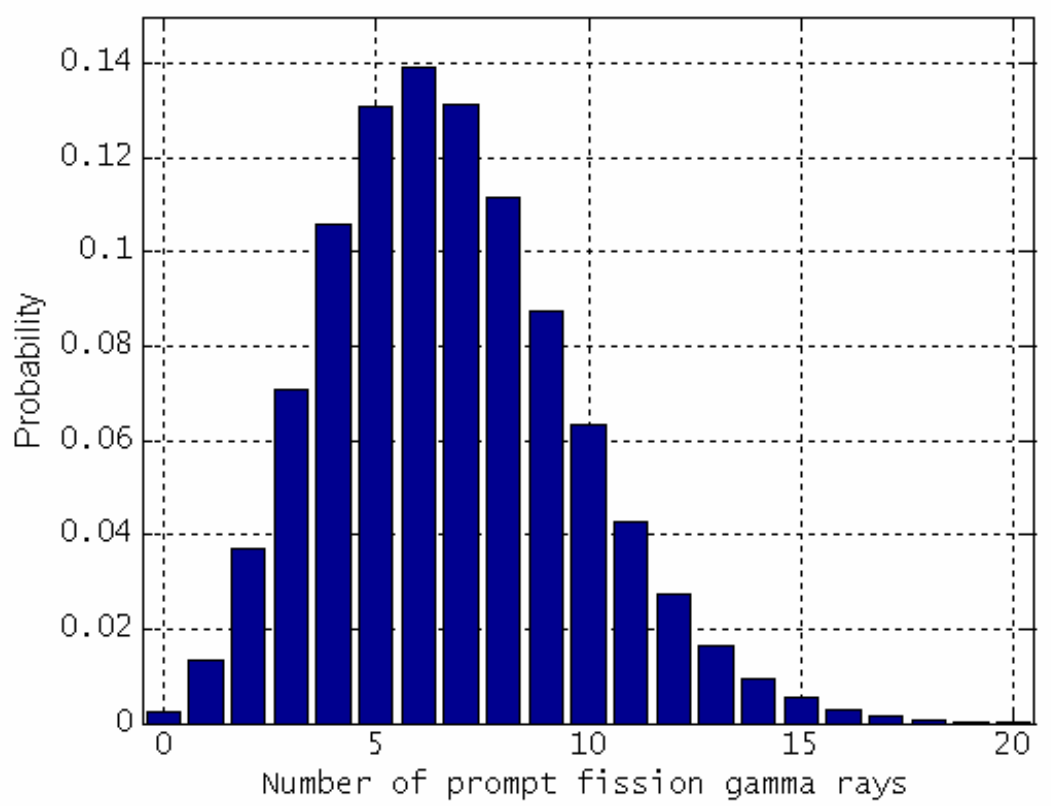

Fig. 2. Thermal neutron induced ${ }^{235} \mathrm{U}$ multiplicity of prompt gamma rays from the negative binomial distribution of Valentine 


\section{TYPES OF MEASUREMENTS}

The measurements can be divided into detection of neutrons and gamma rays. Gamma ray detectors are well known. Gamma ray detection methods can utilize NaI for low energy resolution and HPGe for high resolution gamma ray spectrometry with commercial multichannel analyzers. The number of delayed gamma rays as a function of time could be measured after the sources are turned off. The measurements can be further divided into two types: count rates and

coincident count rates. The latter includes coincidences with the interrogating source, like pulsed neutron measurements and correlations within or between detectors, like Rossi alpha type measurements ${ }^{2}$ and multiplet distributions. ${ }^{1}$ Prompt measurements are more desirable but sometimes their detection is interfered with by high correlated backgrounds from cargo. Delayed neutrons can induce the fission chain multiplication processes between pulses and may not be subject to this correlated background. Before describing the types of measurements that may be useful for the various interrogation sources considered for this application, some examples of the various types of data are presented.

\subsection{COUNT RATES}

The count rate is the normal scalar detection rate seen by a detector. The useful scalar count rate is the count rate above background. The count rate in a detector could change with and without the fissile material present but in this application normal count rate measurements are not practical since there is so much background present that it would be difficult to distinguish the signal produced by the fissile material. However, count rates as a function of time between pulses from an accelerator are related to presence of fissile material and are discussed in Sect. 3.4.3.

\subsection{PROMPT MULTIPLET DISTRIBUTIONS AND MULTIPLICITIES}

In this type of measurement the number of times $n$ pulses occur in a time interval (multiplets) is measured. Deviation of this distribution from Poisson statistics can be a strong indication of the presence of fissile material. ${ }^{1}$ Typical data of this type from a Nuclear Materials Identification System (NMIS) measurement in 1997 with an $18.75 \mathrm{~kg}$ HEU casting is shown in Fig. 3. This data was acquired by a NMIS processor ${ }^{3}$ with 512 one-nanosecond time channels. 


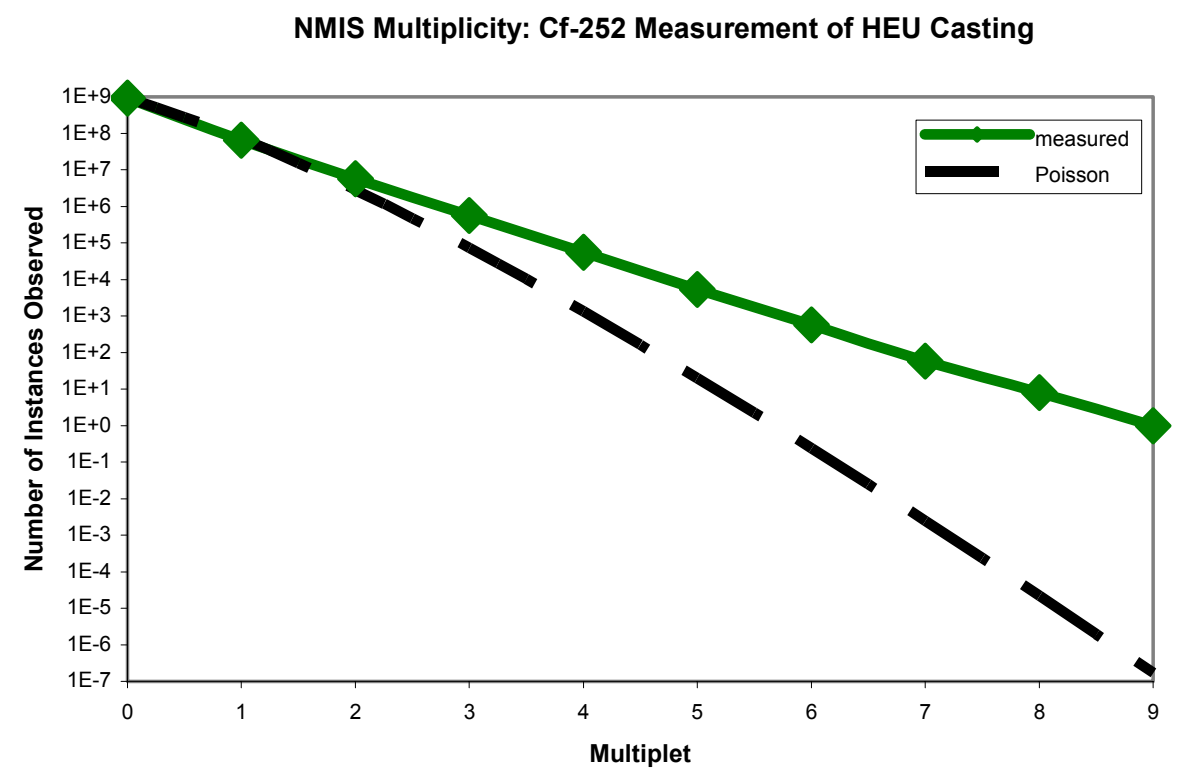

Fig. 3. Number of times n pulses occur in a 512 nsec window from plastic scintillators (from NMIS $\sim 8.5$ minute measurement in 1997) for a HEU $\left(93.2{ }^{235} \mathrm{U}\right) 18.75 \mathrm{~kg}$ metal casting.

The number of $512 \mathrm{nsec}$ time windows for which the multiplets were acquired was $1.0 \times 10^{9}$ in 8.5 minutes. The $18.75 \mathrm{~kg}$ annular HEU storage casting in a stainless steel can had a ${ }^{252} \mathrm{Cf}$ source adjacent to one side and four $3 \times 3$ plastic scintillators on the other side. These detectors were sensitive to neutrons above $1.0 \mathrm{MeV}$ and gamma rays above $150 \mathrm{keV}$. The measured distribution is compared to Poisson statistics and the deviation indicates the presence of fissile material.

In addition, the multiplicities can be obtained from the multiplet distributions. This has been done and is the basis for a widely used nuclear safeguards method using ${ }^{3} \mathrm{He}$ detectors embedded in polyethylene moderator, i.e., the neutron multiplicity method. ${ }^{9}$ NMIS also obtains multiplicities from the multiplet distributions and for plastic scintillators includes both neutron and gamma rays. ${ }^{10}$ 


\subsection{TIME CORRELATION MEASUREMENTS BETWEEN DETECTORS}

The initial measurements of this type were suggested by Rossi in the 1940s as a way of obtaining the prompt neutron decay constant without a pulsed neutron source. ${ }^{2}$ Typical data of this type for the standard HEU storage casting obtained from two plastic scintillators of the same type as described in Sect. 3.2 (but smaller) with a NMIS processor is given in Fig. $4 .{ }^{11}$ In this measurement a Cf source was adjacent to the casting and the detector were on the opposite side. This cross correlation function or time distribution of coincidence counts is composed of three components: (1) gamma-gamma coincidences at time lag 0 because the gamma rays travel at the same speed to the detectors, (2) gamma-neutron coincidences between 5 and 50 nanoseconds and neutron-gamma coincidences between -50 and -5 nanoseconds, and (3) neutron-neutron coincidences spread broadly about time lag zero from -50 to 50 nanoseconds and are much lower in amplitude.

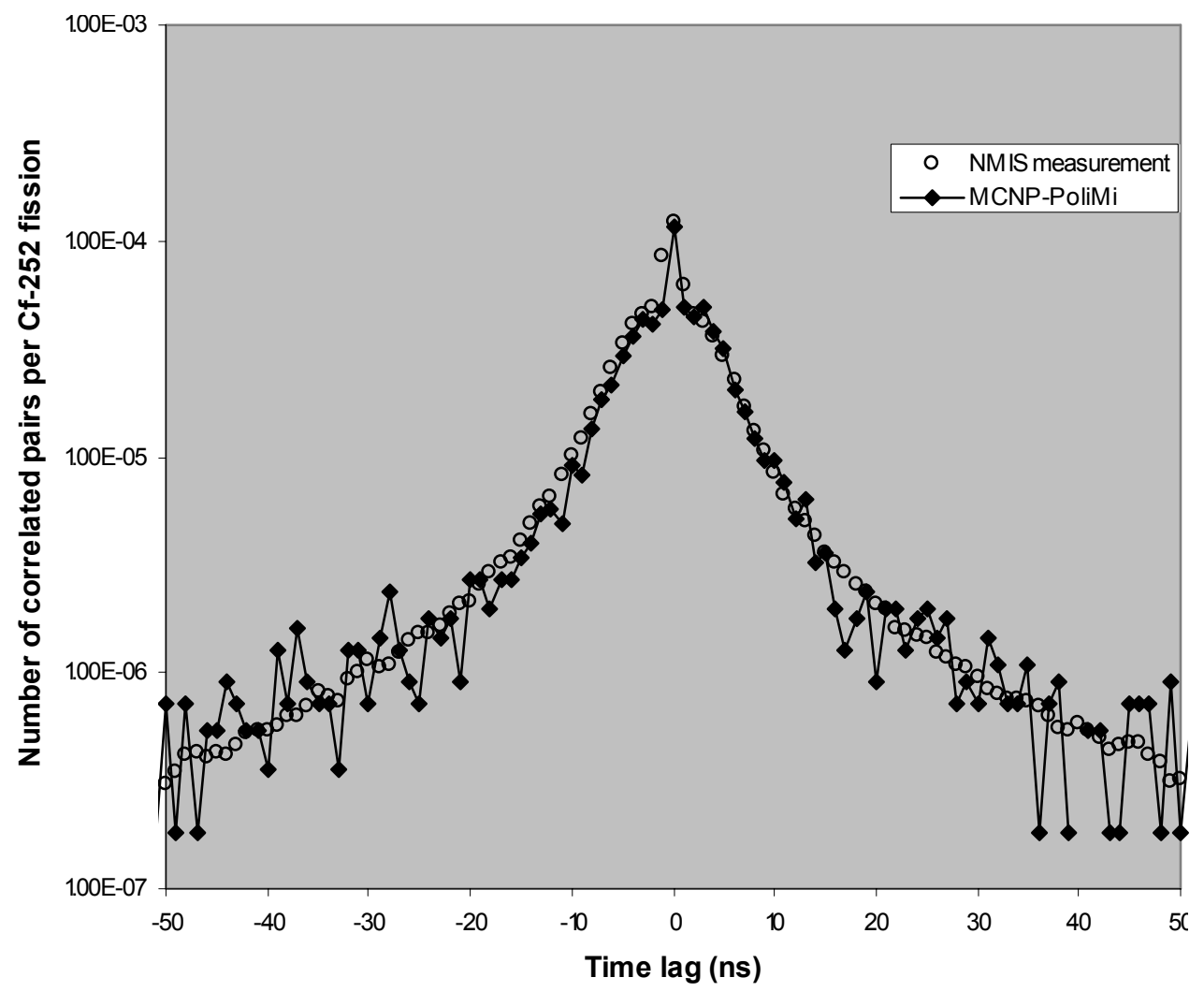

Fig. 4. Time distribution of coincidences between two plastic scintillation detectors for an annular $18.75 \mathrm{~kg}$ HEU $\left(93.2{ }^{235} \mathrm{U}\right)$ metal storage casting. 
This type of passive correlation measurement can also be performed with fissile material with inherent sources such as plutonium. A photograph of a typical arrangement of detectors around a $4 \mathrm{~kg}$ sphere of Pu metal with $1.77 \mathrm{wt} . \% 240 \mathrm{Pu}$ is given in Fig. 5 where one of the detectors has been removed for the photograph (courtesy of Dr. V. Dubinin of the All Russian Institute of Experimental Physics, VNIIEF). The time distribution of coincidences between two 6x6x4-inthick plastic scintillation detectors on opposite sides is given in Fig. 6 where Monte Carlo calculations are compared to the measurements ${ }^{6}$. This data is included as typical for cases where delayed neutrons from previous fissions in HEU can act as an inherent source.

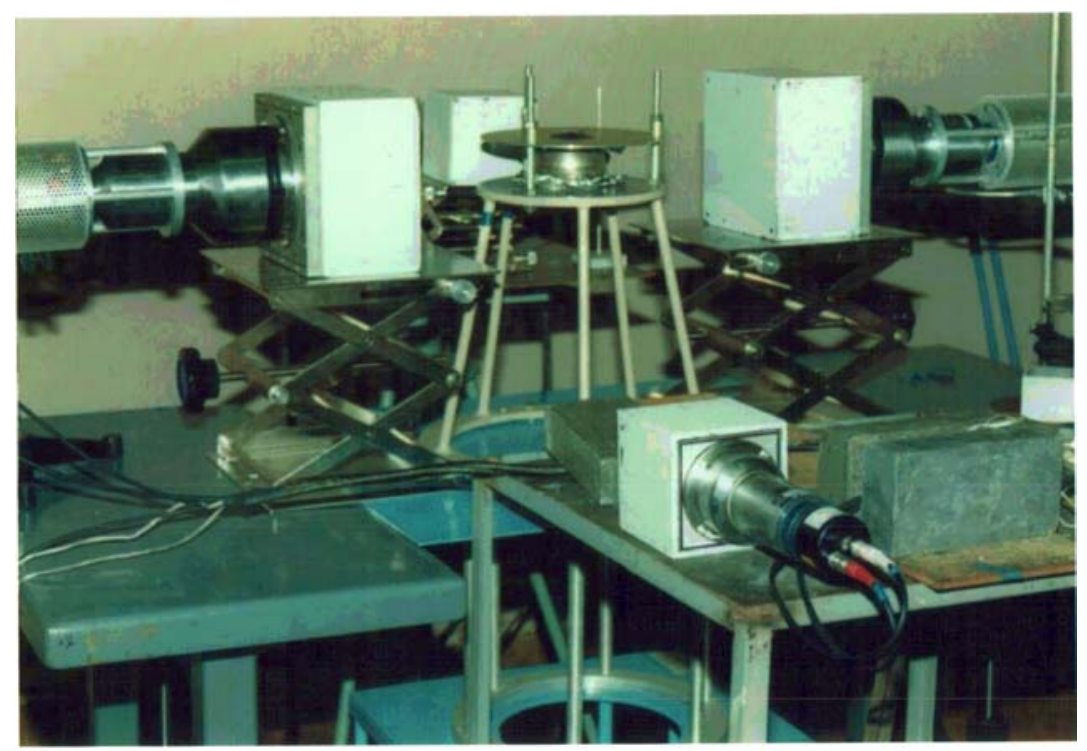

Fig. 5 Photograph of the plastic scintillator arrangement and a $4 \mathrm{~kg} \mathrm{Pu}$ Metal $(1.77 \% 240 \mathrm{Pu})$ spherical shell with one detector removed.

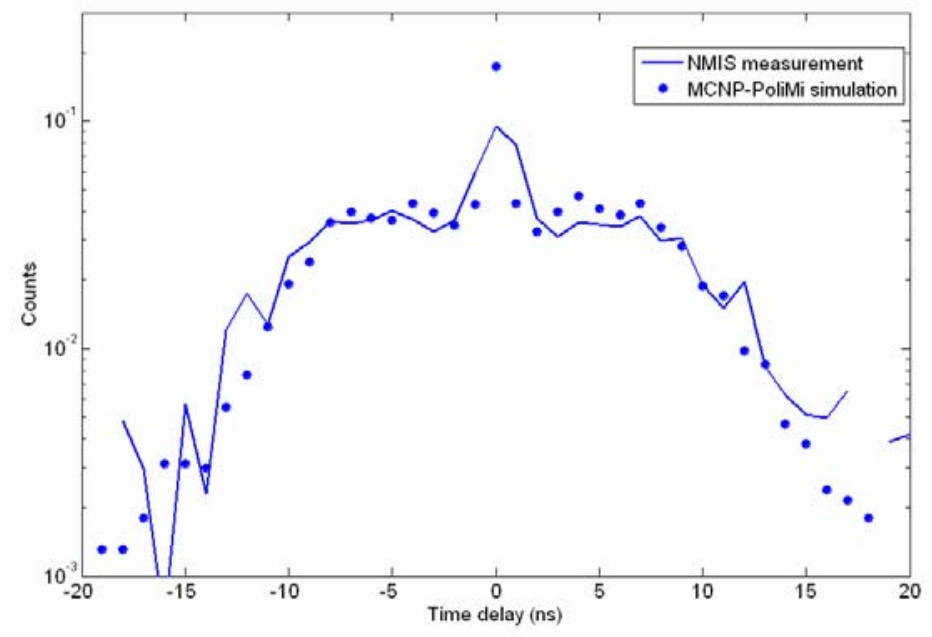

Fig. 6 Time distribution of coincidences between two plastic scintillation detectors for a $3.3 \mathrm{Kg}$ Pu Metal (1.77 wt of ${ }^{240} \mathrm{Pu}$ ) spherical shell 


\subsection{PULSED SOURCE MEASUREMENTS}

In this type of measurement an interrogating source (neutron or high energy gamma rays) is pulsed and the time dependence of the detector response between pulses is measured in a variety of ways and for a variety of sources. The prompt or delayed time dependence of radiation from induced fission is measured between pulses after source initiation.

\subsubsection{PROMPT TIME DEPENDENCE}

The neutron or gamma count rate (or some combination) is measured after source initiation between pulses. Data from a pulsed neutron measurement with a Cockroft-Walton DT neutron generator for an HEU (93 wt \% 235) metal assembly (11-in.-OD, 2.5-in.-high) measured with a plastic scintillation detector is given in Fig. 7. ${ }^{12}$ The generator produced $30 \mathrm{nsec}$ pulses at $0.9 \mathrm{MHz}$ repetition rates and the prompt time response was measured between pulses. The detector was a thin plastic scintillator sensitive to neutron and gamma rays and the zero of time shifted in the electronics by delay of the signal with respect to the pulses to measure the background before the pulse and the rising portion of the pulse.

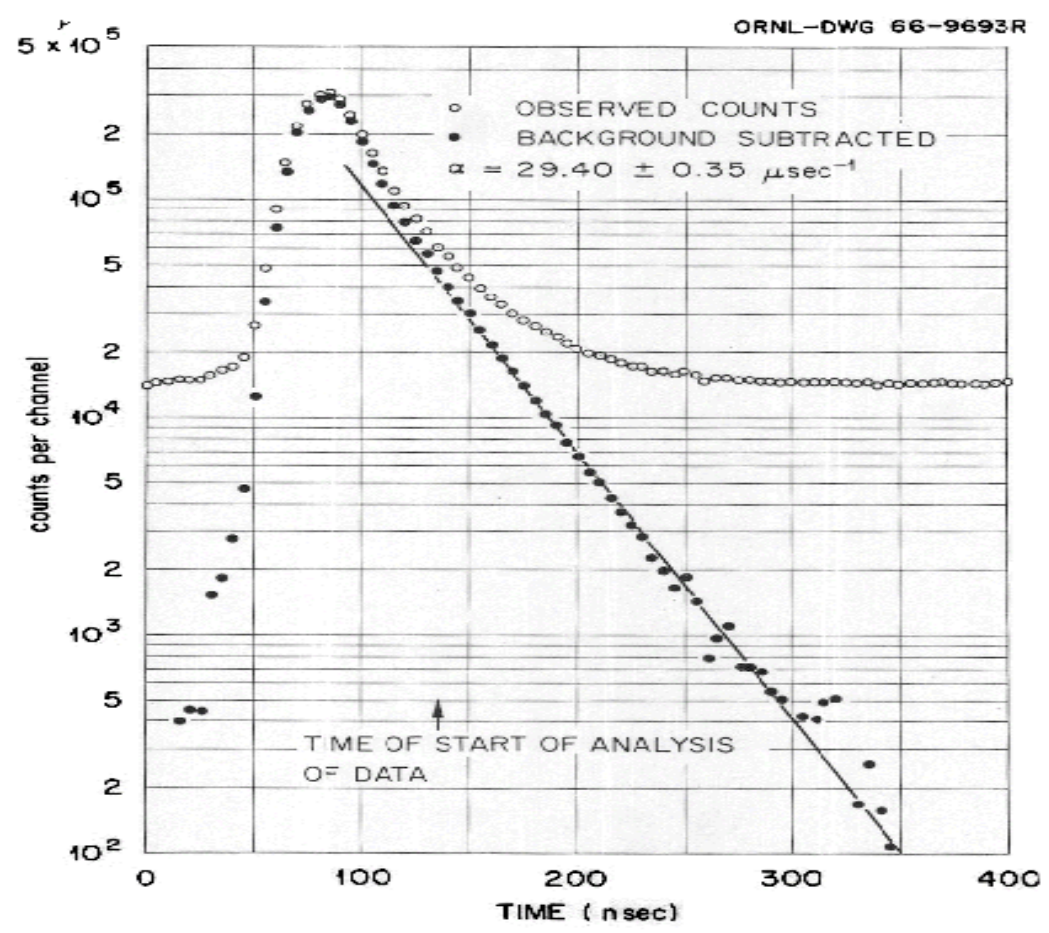

Fig. 7. Time distribution of count after $30 \mathrm{nsec}$ accelerator pulses for an 11-in.-diam, 2.5-in.-high HEU cylinder.

Another way to perform the measurement of the time distribution of counts after fission is with a randomly pulsed neutron source such as time tagged $\mathrm{Cf},{ }^{13}$ which spontaneously fissions, or with a DT generator with an alpha detector. Typical data of this type with a time tagged Cf source for the HEU casting described above in the multiplet section but obtained with one of the 
$3 \times 3 \times 4$-in.-thick plastic scintillator is given in Fig. 8 where it is also compared to Monte Carlo calculations. ${ }^{11}$ The time distribution consists of several components: (1) direct gamma rays which pass through the casting and occur at the flight time of the gamma rays, (2) transmitted high energy neutrons at about 5 nanoseconds, (3)scattered neutrons, and (4) neutrons and gamma rays from induced fission. The initial peak at $\sim 1$ nanoseconds is from transmitted gamma rays from the source followed by scattered neutrons and then fission neutrons.

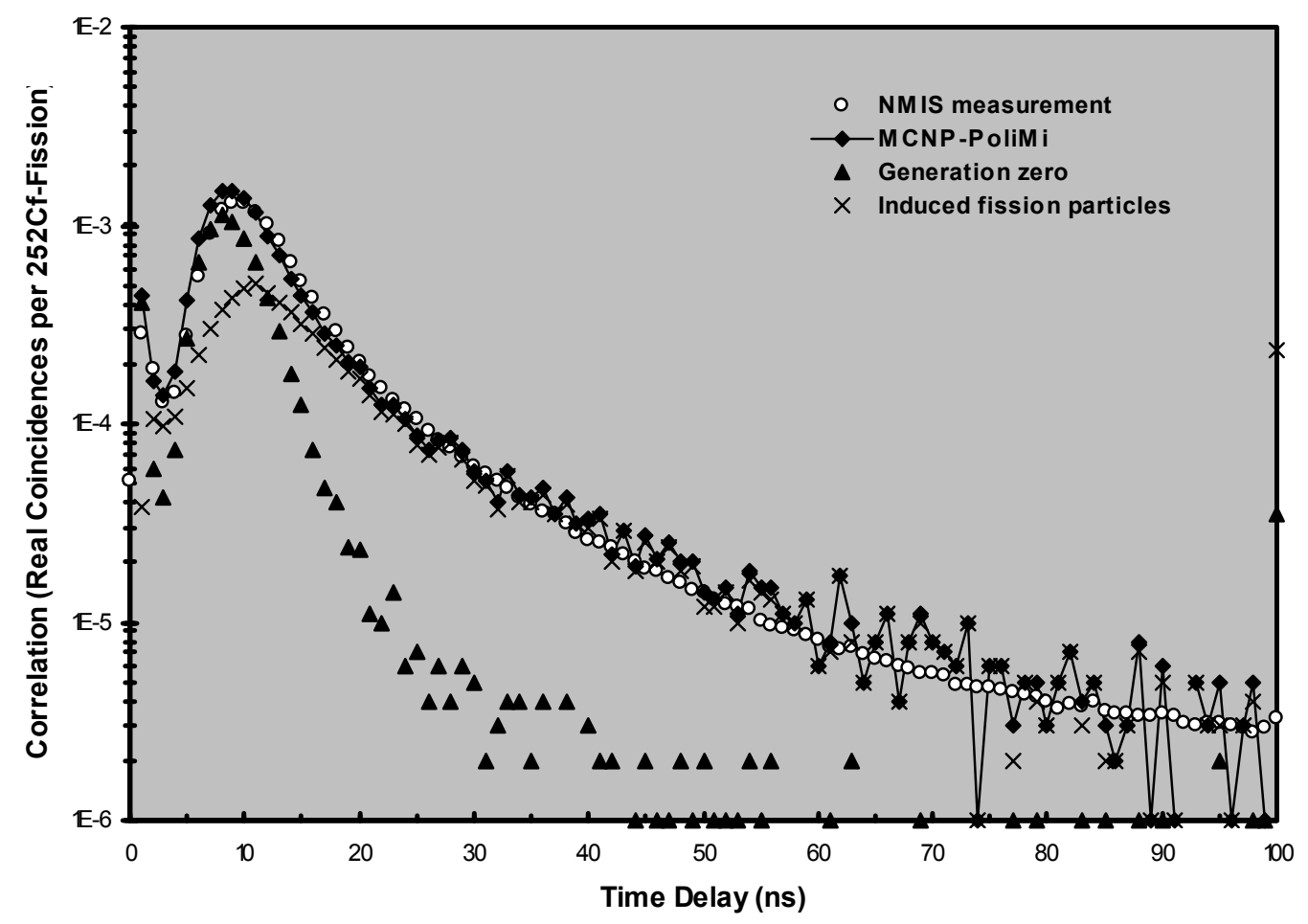

Fig. 8. Time distribution of counts in a plastic scintillator after Cf fission for an annular $18.75 \mathrm{~kg}$ HEU metal storage

\subsection{DIFFERENTIAL DIEAWAY}

In these measurements ${ }^{14}$ the time dependence of the neutron count rate immediately after the accelerator pulse has been measured with ${ }^{3} \mathrm{He}$ counters embedded in moderators. Typical data from a package monitor at LANL is shown in Fig. 9 for various materials. In this measurement, the decay of the moderated neutrons is measured after the accelerator pulse of $14 \mathrm{MeV}$ neutrons from a DT generator. In this case the accelerator source was repetitively pulsed. Another way to perform this measurement would be operate the source in a steady state mode, say for a few seconds and turn it off and measure the decay of the neutron population.

\subsubsection{DELAYED NEUTRON COUNT RATE BETWEEN PULSES}

In LINAC measurements, the count rate between pulses with ${ }^{3} \mathrm{He}$ counters embedded in moderators has been measured and a typical result for these measurements is given in Fig. $10{ }^{15}$ The count rate between pulses is from: (1) prompt neutrons generated from induced photo fissions in the nuclear material, (2) delayed neutrons from induced photo fission by the source 
that leak to the detectors, and (3) prompt neutrons from fissions induced by the delayed neutrons that do not leak from the system. The ratio of the two components to the signal depends on the fissile mass since the ratio of leakage to fission depends on mass. The two components are equal for a $5 \mathrm{~kg}$ sample of HEU $\left(\sim 03 \mathrm{wt} \%{ }^{235} \mathrm{U}\right)$. This type of measurement could be performed for any of the pulsed sources of interrogating radiation.

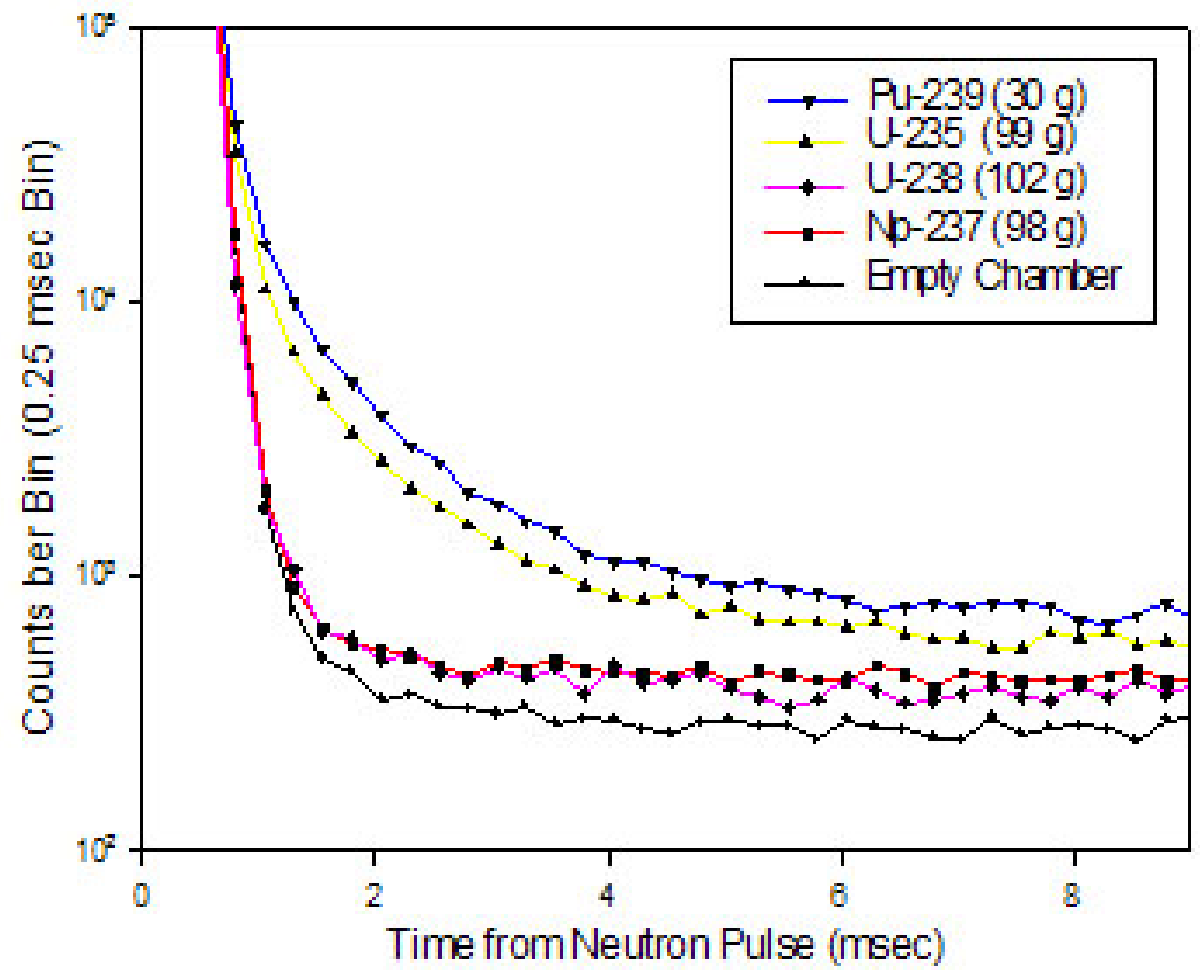

Fig. 9. Typical differential dieaway data from a package monitor at LANL (courtesy of C. Moss).casting 


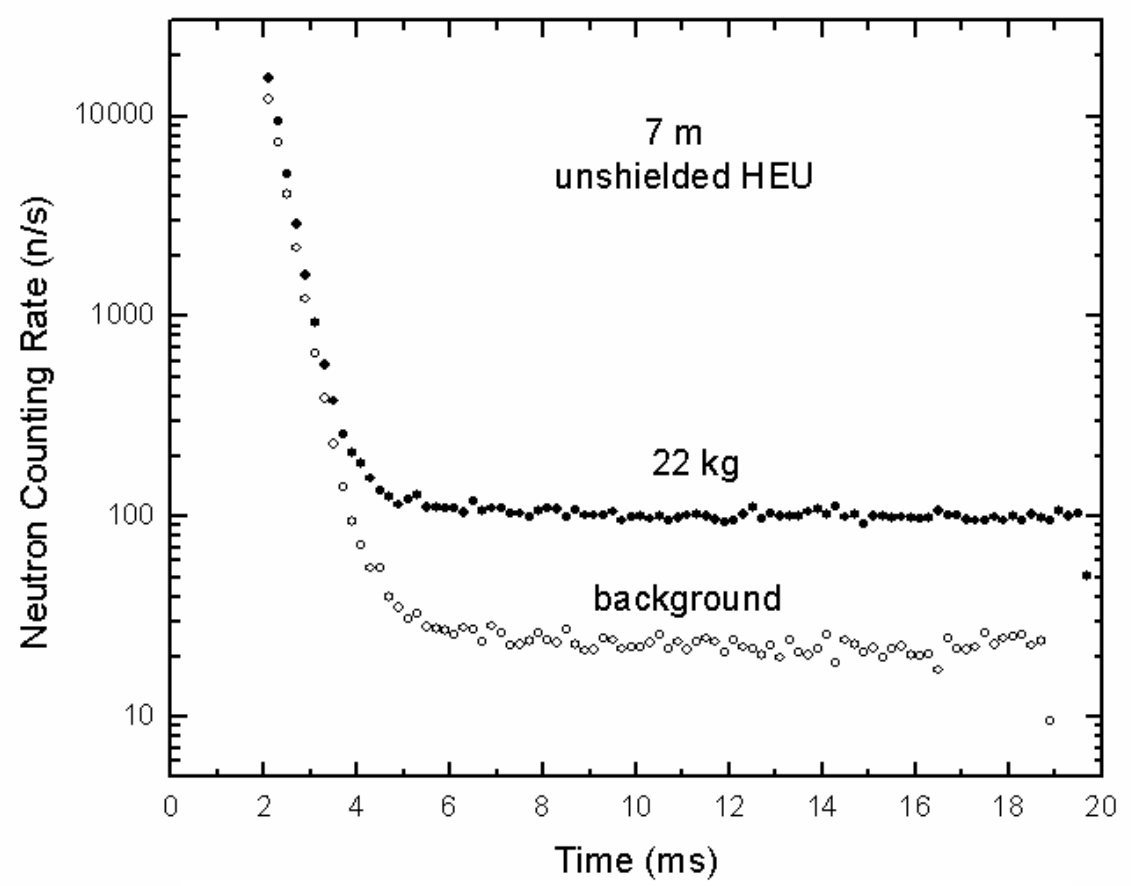

Fig. 10 Response with Linac and large-area detector.

\subsection{DELAYED GAMMA ENERGY SPECTRA}

The gamma ray energy spectra can be measured with commercial HPGe measurement systems with high resolution and can be measured with commercial $\mathrm{NaI}$ based systems for lower resolution measurements. ${ }^{16}$

\section{DETECTORS}

Detectors for this application are sensitive to fast neutron, gamma rays, and thermal neutrons. For this application the detectors have to be high sensitivity, large area systems, probably at least $8 \times 8$ feet on at least 2 sides of the sealand container.

\subsection{THERMAL NEUTRON DETECTORS}

Thermal neutron detectors have usually been ${ }^{3} \mathrm{He}$ proportional counters embedded in polyethylene with the moderator configured for the particular measurement. A photograph of a large $4 \times 8$ panel of ${ }^{3} \mathrm{He}$ detectors used at LANL is given in Fig. $11 .{ }^{17}$ A smaller $51 \times 43 \times 10 \mathrm{~cm}$ more portable system of several ${ }^{3} \mathrm{He}$ counters in moderation is shown in Fig. 12. A photograph of a single ${ }^{3} \mathrm{He}$ counter used at INEL in photofission measurements with a LINAC is given in Fig. 13. ${ }^{18}$ Other types of thermal neutron detectors could contain boron or ${ }^{6} \mathrm{Li}$. A photograph of large panels of ${ }^{6} \mathrm{Li}$ containing glass fibers at PNNL sensitive to thermal neutrons is given in Fig. $14 .{ }^{19}$ 

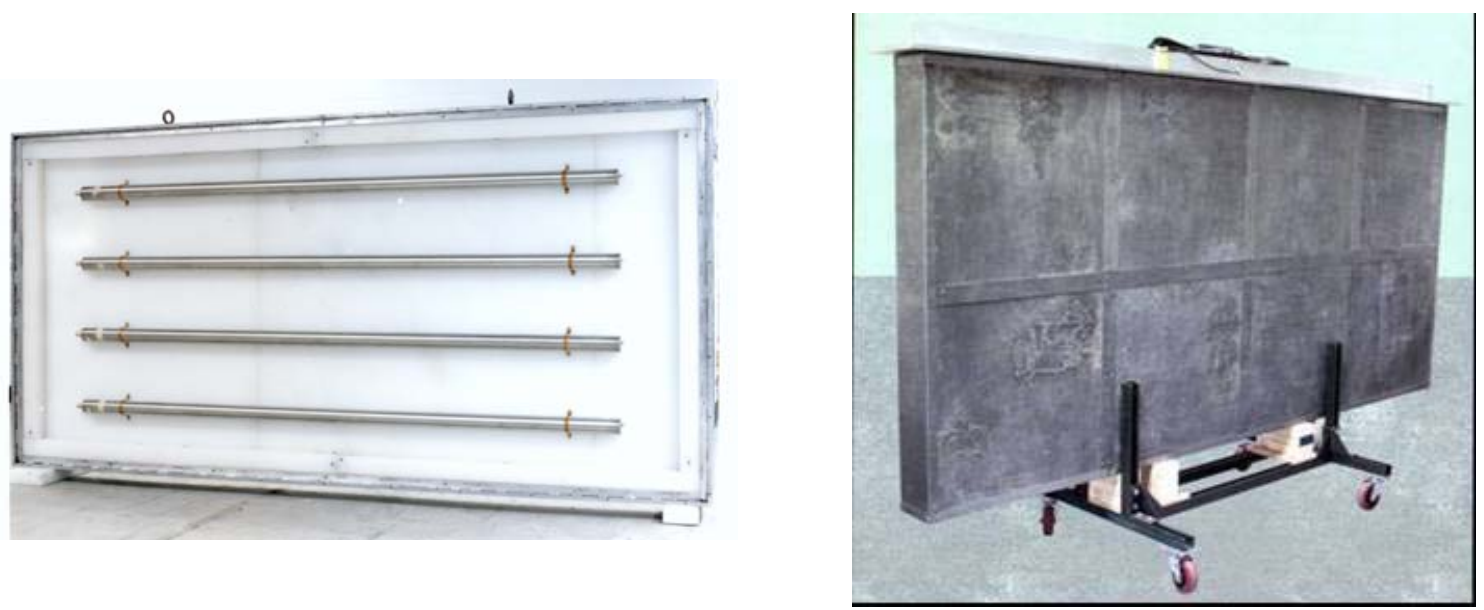

Fig. 11 Large-area $(4 \times 8 \mathrm{ft}),{ }^{3} \mathrm{He}$ neutron detector panel.

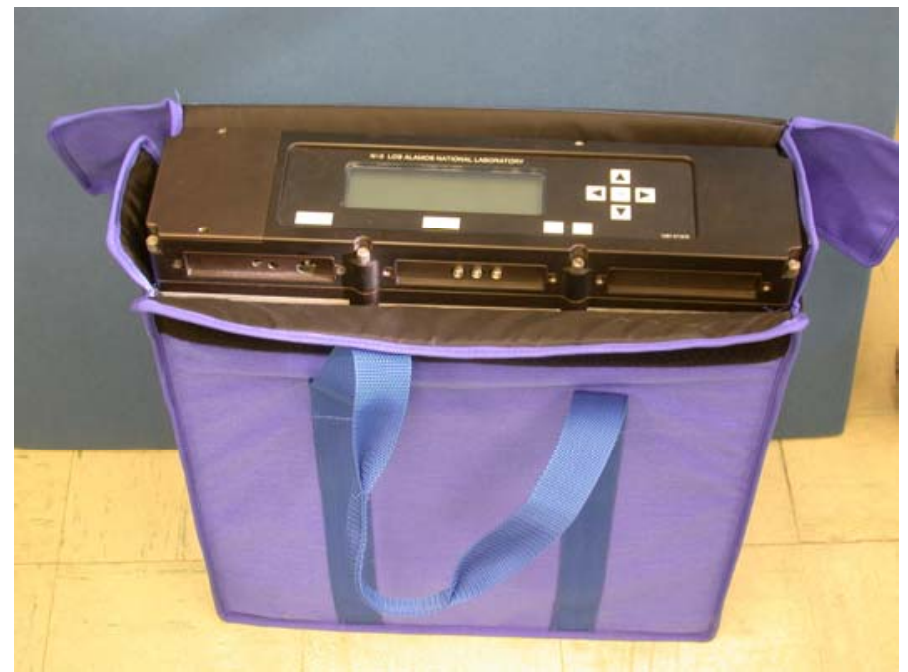

Fig. 12. Portable ${ }^{3} \mathrm{He}$ detector in moderator (51 $\times 43 \times 10 \mathrm{~cm}$ dimensions). 


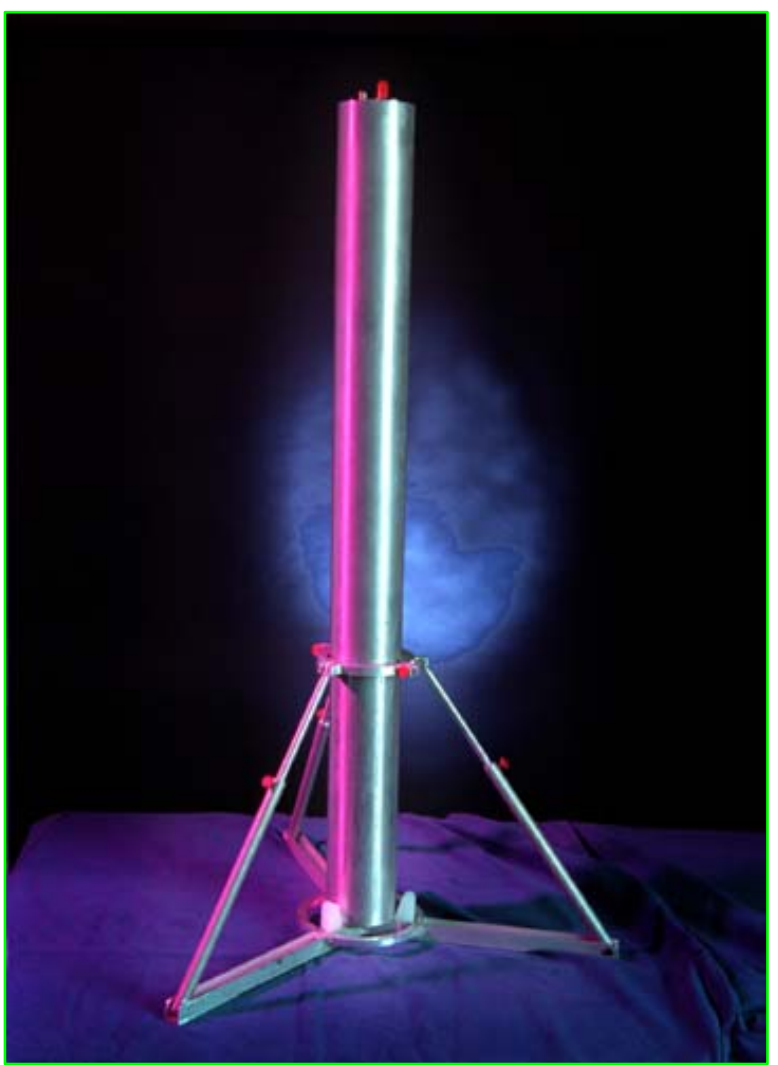

Fig. 13. INEL's ${ }^{3}$ He proportional counter for pulsed LINAC photo fission measurements.

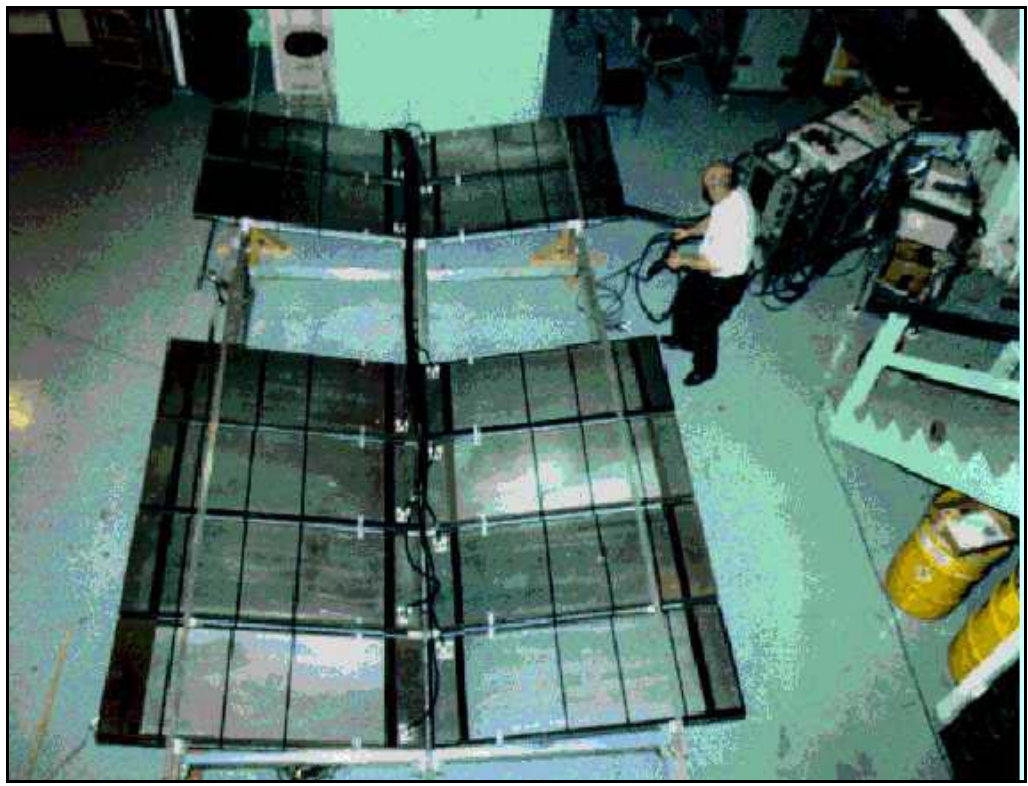

Fig. 14. Large panels of ${ }^{6} \mathrm{Li}$ glass fiber thermal neutron detectors. 


\subsection{PLASTIC SCINTILLATORS}

Fast plastic scintillators, sensitive to fast neutrons and gamma rays without distinction, are available with nanosecond time resolution. They have efficiency for $2 \mathrm{MeV}$ neutron detection of $60 \%$ per hit on the front face of an 8-cm-thick detector and about $40 \%$ for unshielded fission gamma rays. Large plastic scintillator arrays could be made up of $1 \times 1$ meter plastic sheets with two photomultipliers per module. A photograph if a $1 \times 1$ meter plastic scintillator $(8.0-\mathrm{cm}$-thick) covered with Lexan with two scintillation detectors centered on opposite thin surfaces is given in Fig. $15 .^{20}$

In the photograph, a ${ }^{22} \mathrm{Na}$ gamma ray source time tagged by a smaller plastic scintillator above it is shown near the center of the $1 \times 1$ meter detector during testing at ORNL. This $1 \times 1$ meter detector with coincident counting between the 2 scintillation detectors tubes has $\sim 2 \mathrm{nsec}$ time resolution and satisfactory uniform response across the surface.

A combined detector which contains a $1 \times 1$ meter array of ${ }^{6}$ Li Glass fibers adjacent to a $1 \times 1$ meter plastic scintillator is under fabrication at the NUCSAFE Corporation and would be sensitive to fast neutrons, gamma rays and thermal neutrons.

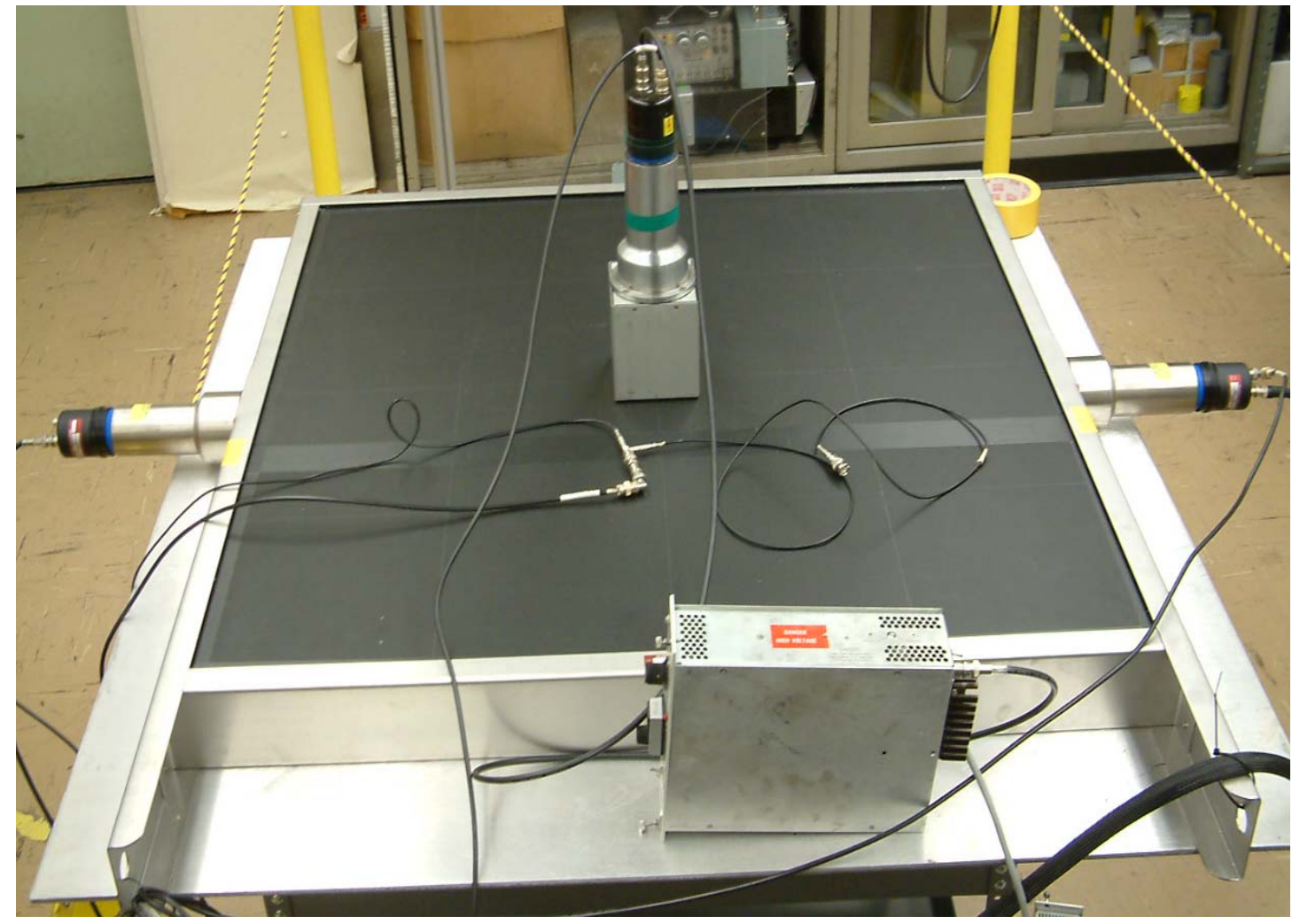

Fig. 15. Photograph of a $1 \times 1$ meter plastic scintillator in testing at ORNL.

\subsection{LIQUID SCINTILLATORS}

Liquid scintillators are another type of fast organic scintillator that are sensitive to fast neutrons and gamma rays with the ability to distinguish between fast neutrons and gamma rays and provide more information. A collection of $5.1 \times 5.1 \times 200 \mathrm{~cm}$ liquid scintillators has been 
assembled into a $2 \times 2$ meter array for physics measurements by Michigan State University for use at Fermi Laboratory. ${ }^{21}$ However, they have the disadvantage in that the liquid can leak and may require a large number of photomultiplier tubes to maintain the pulse shape discrimination capability.

\subsection{DETECTION FOR GAMMA RAY SPECTROMETRY}

Gamma ray detectors are well known and gamma ray detection methods can utilize NaI for low energy resolution and HPGe for high resolution gamma ray spectrometry with commercial multichannel analyzers.

\section{INTERROGATION SOURCES}

Various interrogation sources are being considered for application to detection of shielded HEU in sealand containers. This section briefly describes he interrogation sources that may be useful for this application The sources are:

1) Proton accelerator using the $\mathrm{H}(\mathrm{p}, \mathrm{n}) 7 \mathrm{Li}$ reaction to produce $60 \mathrm{keV}$ neutrons in the forward direction ${ }^{[22]}$.

2) DT generator producing $14.1 \mathrm{MeV}$ neutrons isotropically ${ }^{24}$, detecting prompt neutrons after the accelerator pulse is turned off or time correlation measurement with the source, and detection of multiplets and correlation between detectors between pulses.

3) DT generator producing $14.1 \mathrm{MeV}$ neutrons isotropically ${ }^{25,26}$, differential dieaway between accelerator pulses (PFNA).

4) Photofission from 4-14 MeV discrete gamma rays from a 1-2 MeV proton accelerator ${ }^{27}$

5) Neutron inducd fission from thermalized $2.5 \mathrm{MeV}$ neutrons from a DD generator

6) Photofission by 6-7 MeV gamma rays from a 3-4 MeV proton accelerator utilizing the ${ }^{19} \mathrm{~F}(\mathrm{p} \alpha \gamma){ }^{16} \mathrm{O}$ reaction ${ }^{28}$

7) Thermal neutron induced fission from $14.1 \mathrm{MeV}$ DT neutron generator ${ }^{29,30}$ detection of delayed gamma rays above $3 \mathrm{MeV}^{31}$.

8) MeV Photon (bremstralung from a LINAC) induced fission with delayed neutron detection ${ }^{15,32}$

9) Pulsed photonuclear assessment with a 10-20 Mev photon (bremstralung from a LINAC) induced fission ${ }^{33,34}$ with delayed neutron and delayed gamma detector.

10) Nuclear Resonance fluorescence induced by an $8 \mathrm{MeV}$ LINAC $^{35}$ and detection of gamma rays with high purity Ge detectors.

The detection method for the last source listed does not detect fission emissions, but characteristic nuclear resonance fluoresense gamma rays emitted by the nucleus of a particular isotope. This source will also induce photofission in HEU. The sources can be divided into neutron, both $60 \mathrm{keV}$ from proton accelerators and high energy neutrons from DD or DT neutron generators, and gamma ray produced by proton accelerators producing monoenergetic gamma emissions or LINAC emitting bremstrahlung spectra. In addition, a simple change of target in a LINAC would provide an interrogating neutron source.

\section{DATA PROCESSING}

Data processing methods include gamma ray spectrometry and time coincidence methods with the interrogating source or coincidences between detectors.

Gamma ray detectors are well known and gamma ray detection methods can utilize NaI for low energy resolution and HPGe for high resolution gamma ray spectrometry with commercial 
multichannel analyzers. Delayed gamma ray as a function of time could be measured after the sources are turned off. Similar measurements could be made for delayed neutrons.

There are a variety of ways to acquire other data: count rate, count rate as a function of time after interrogation source pulsing, and coincident count rate between multiple detectors during or between source pulses. Various commercial multichannel time analyzers can record the time distribution of counts after source initiation of fission chains. Standard microsecond resolution processing is available for multiplet measurements or multiplicity measurements with ${ }^{3} \mathrm{He}$ counters embedded in polyethylene. NMIS processing can obtain correlations between detectors, between a detector and the source, and the multiplet distributions for measurements on the time scale of the fission chain multiplication processes ( 1 nanosecond time channels), this processor for 10 channels of data requires 4 slots in a PC and appropriate software. For 5 channels of operation the NMIS processor is capable of on-line processing at rates of over $2 \times 10 \mathrm{E} 6$ events in each channel without loss of any information and can calculate on-line all 15 cross correlations and multiplets. The NMIS processor is deeply buffered to handle large fission chains. Short time scale measurements have the advantage of lower accidental coincidences and fission chain shape information is obtained. Measurements are routinely made with this fast processor for signal to noise ratios of $1 \times 10 \mathrm{E}^{-3}$.

\section{SUMMARY MATRIX}

The various interrogating sources and the methods of detection are summarized in the following Table 4. Potential measurements are presented. For high time resolution measurements with organic scintillators, sensitive to neutrons above $0.5 \mathrm{MeV}$, the scintillators would not be sensitive to the $60 \mathrm{keV}$ source neutrons and measurements could be performed when the $60 \mathrm{keV}$ source is on. Of course, for hydrogenous cargo there may be appreciable background from neutron capture. For other pulsed sources the scintillation detectors would have to be gated off during the source interrogation pulse. Gamma-gamma, gamma-neutron, and neutron-neutron coincidences could be obtained for all sources, either between or in some cases during the active interrogation by the source. For some highly moderated cargo, only gamma rays from induced fission reach the detectors and produce all of the coincidences. The sources can be divided into two classes: neutron and gamma sources with a variety of detection methods. Many of the detection methods are common to many of the interrogating sources. LINAC sources can be used to produce neutrons or bremsstrahlung spectra by changing targets. 
Table 4. Matrix of Interrogating Sources and Potential Measurements

\begin{tabular}{|c|c|c|c|c|c|c|c|c|}
\hline \multirow[b]{2}{*}{ Interrogation source } & \multicolumn{3}{|c|}{ Prompt time correlations } & \multicolumn{3}{|c|}{ Delayed time correlations } & \multirow[b]{2}{*}{ Count rate } & \multirow{2}{*}{$\begin{array}{l}\text { Gamma ray } \\
\text { spectrometry }\end{array}$} \\
\hline & Multiplets & $\begin{array}{c}\text { With } \\
\text { source }\end{array}$ & $\begin{array}{l}\text { Detector } \\
\text { detector }\end{array}$ & Multiplets & $\begin{array}{c}\text { With } \\
\text { source }\end{array}$ & $\begin{array}{l}\text { Detector } \\
\text { detector }\end{array}$ & & \\
\hline $\begin{array}{l}\text { 1. Low energy stimulated } \\
\text { multiplication }(60 \mathrm{KeVn})\end{array}$ & $\mathrm{DP}^{a}$ & BP & DP & BP & BP & BP & BP & - \\
\hline $\begin{array}{l}\text { 2. High energy stimulated } \\
\text { multiplication }(14.1 \mathrm{MeVn})\end{array}$ & $\mathrm{SS}^{b}$ & $\mathrm{SS}^{b}$ & $\mathrm{SS}^{b}$ & BP & BP & BP & $\mathrm{BP}$ & - \\
\hline 3. PFNA (14.1 MeVn) & - & - & - & BP & $\mathrm{AP}^{c}$ & BP & $\mathrm{BP}$ & - \\
\hline $\begin{array}{l}\text { 4. High energy monoenergetic } \\
\text { photofission (4-14 MeVp) } \\
\text { 5. Neutron induced fission from }\end{array}$ & - & - & - & BP & BP & BP & BP & HPGe \\
\hline $\begin{array}{l}\text { thermalized } 2.5 \mathrm{MeVn} \\
\text { 6. Monoenergetic Photon induced }\end{array}$ & DP & - & DP & BP & $\mathrm{AP}$ & BP & BP & - \\
\hline $\begin{array}{l}\text { fission }(6-7 \mathrm{MeVp}) \\
\text { 7. Thermal neutron induced fission }\end{array}$ & $\mathrm{SS}$ & - & $\mathrm{SS}$ & BP & AP & BP & BP & HPGe \\
\hline $\begin{array}{l}\text { (14.1 MeVn) } \\
\text { 8. Thermal neutron induced fission }(5-\end{array}$ & - & - & - & BP & - & BP & BP & - \\
\hline $\begin{array}{l}8 \mathrm{MeVn} \text { ) } \\
\text { 9. Photon (bremstralung) induced } \\
\text { fission, delayed neutron detection }\end{array}$ & - & - & - & - & - & - & - & $>3 \mathrm{MeV}$ \\
\hline $\begin{array}{l}\text { (7-9 MeVp) } \\
\text { 10. Pulsed photonuclear assessment }\end{array}$ & - & AP & - & BP & AP & BP & BP & - \\
\hline $\begin{array}{l}\text { (PPA) bremstrahlung }(10-20 \mathrm{MeVp}) \\
\text { 11. Nuclear Resonance Fluorescence }\end{array}$ & - & AP & - & $\mathrm{BP}$ & AP & $\mathrm{BP}$ & $\mathrm{BP}$ & HPGe \\
\hline (8 MeV brehmstralung) & 一 & 一 & 一 & - & 一 & & 一 & HPGe \\
\hline
\end{tabular}

$a_{\mathrm{BP}}$ means between pulses, DP means during source interrogation, and AP means immediately after pulsing.

$b_{\text {DT }}$ generator operated steady state with alpha detector to define a cone of neutrons.

${ }^{c}$ Differential dieaway. 


\section{REFERENCES}

1. R. Dierckx and W. Hage, Neutron Signal Multiplet Analysis for the Mass Determination of Spontaneous Fission Isotopes, Nuclear Science and Engineering: 85, 325-338 (1983).

2. J. D. Orndoff, Nuclear Science Engineer: 2, 450-460 (1957).

3. J. T. Mihalczo, et al., Physical Description of Nuclear Materials System (NMIS) Signatures, Nuclear Instruments \& Methods in Physics Research, Section A, 450, 531555 (2000).

4. G. R. Keepin, T. F. Wimmett, and R. K. Zeigler, R. K., Physics, 107, 1044 (1957).

5. José March-Leuba, J. K. Mattingly, J. A. Mullens, T. E. Valentine, J. T. Mihalczo, and

R.B. Perez, Methodology for Interpretation of Fissile Mass Flow Measurements, $38^{\text {th }}$ Annual Meeting of the Institute of Nuclear Materials Management, Phoenix, Arizona, July 20, 1997.

6. R. Vandenbosch and J. R. Huizenga, Nuclear Fission, Academic Press, New York (1973).

7. G. S. Brunson, Jr., Multiplicity and Correlated Energy of Gamma Rays Emitted in the Spontaneous Fisson of Californium-252, Ph.D. Thesis, University of Utah (1982).

8. T. E. Valentine, Evaluation of Prompt Fission Gamma Rays for Use in Simulating Nuclear Safeguards Measurements, Annals of Nuclear Energy, 28, 191-201 (2001).

9. D. M. Cifarelli and W. Hage, Models for a Three-Parameter Analysis of Neutron Signal Correlation Measurements for Fissile Material Assay, Nuclear Instruments and Methods in Physics Research A251, 550-563 (1986).

10. Perez, J. L. Munoz-Cobo, T. E. Valentine, J. T. Mihalczo, and J. A. Mullens, Incorporation of Neutron and Gamma Multiplicity Measurements in the ORNL Nuclear Materials Identification System (NMIS): Passive and Active Measurements, paper presented at the Institute of Nuclear Materials Management Conference, Phoenix, Arizona, July 25-30, 1999.

11. S. A. Pozzi, J. K. Mattingly, and J. T. Mihalczo, Validation of the MCNP-Polimi Code for the Simulation of Nuclear Safeguards Experiments on Uranium and Plutonium Metal, Nuclear Mathmatics and Computer Science: A Century in Review, A Century Anew, Gatlinburg, Tennessee, April 6-11, on CD Rom, ANS (2003).

12. J. T. Mihalczo, Nuclear Science and Engineering, 32, 292-301 (1968).

13. J. T. Mihalczo, Nuclear Science and Engineering, 53, 393-414 (1974).

14. J. Bendahan, D. R. Brown, T. Gozani, R. A. Loveman, J. C. Rynes, and J. Stevenson, "Detection of SNM in Vehicles and Cargo Containers by Pulsed Fast Neutron Analysis," $39^{\text {th }}$ Annual Meeting of the Institute of Nuclear Materials Management, July 1998, Naples, Florida.

15. J. L. Jones, W. Y. Toon, Y. D. Harker, J. M. Hoggan, K. J. Haskell, and L. A. VanAusdein, Proof-of-Concept Assessment of a Photofission-based Interrogation System for the Detection of Shielded Nuclear Material, Idaho Nuclear Engineering Laboratory, INEEL/EXT-2000-01523, 2000.

16. E. B. Norman, S. G. Prussin, R. M. Larimer, H. Shugart, E. Browne, A. R. Smith, R. J. McDonald, H. Nitsche, P. Gupta, M. I. Frank, and T. B. Gosnell, Signatures of Special Nuclear: High-Energy $\gamma$-Rays Following Fission, Nuc. Inst. Meth. A, 521/2, 608, 2004.

17. C. E. Moss, C. A. Goulding, C. L. Hollas, and W. L. Myers, Linear Accelerator-based Active Interrogation for Detection of Highly Enriched Uranium, IEEE Trans. Nuc. Sci., Portland, OR, IEEE, October 19-25, 2003.

18. J. L. Jones, K. J. Haskell, J. M. Hoggan, D. R. Norman, and W. Y. Yoon, Photonuclearbased Detection of Nuclear Smuggling in Cargo Containers, Conference on Accelerator Applications in Research and Industry, Denton, Texas, November 12, 2002. 
19. Ronald L. Brodzinski, PNL (2004).

20. J. S. Neal and J. T. Mihalczo, Large Plastic Scintillation Detectors for the Nuclear Materials Identification System, Institute of Nuclear Materials Management Annual Meeting, Orlando, Florida, July 18-22, 2004.

21. P. D. Zecher et al., A Large-area, Position-sensitive Neutron Detector with Neutron/ $\gamma$-ray Discrimination Capabilities, Nuclear Instruments and Methods in Physics Research Section A: Accelerators, Spectrometers, Detectors and Associated Equipment, Volume 401, Issues 2-3, 329-344, December 21, 1997.

22. D. D. Dietrich, The Use of 60keV Neutrons in Primary Screening, CAARI $200418^{\text {th }}$ International conference on Application of Accelerators in Research and Industry, October 10-15, 2004, Fort Worth, Texas, LLNL

23. J. T. Mihalczo, J. A. Mullens, J. K. Mattingly, T. E. Valentine, "Physical description of nuclear materials identification system (NMIS) signatures", Nuc. Inst. Meth. A 450, 531-555 (2000).

24. S. A. Pozzi, J. T. Mihalczo, "Monte Carlo evaluation of the improvements in nuclear materials identification system (NMIS) resulting from DT neutron generator ", Oak Ridge National Laboratory, Y/LB-16, June 23-27, 2002.

25. T. Gozani, "Understanding the physics limitations of PFNA - the nanosecond pulsed fast neutron analysis", Nuc. Inst. Meth. B 99, 743-747 (1995).

26. T. Gozani et al, "Nanosecond PFNA Inspection for a Wide Rang of Threats from Luggage to Trucks, CAARI $200418^{\text {th }}$ International conference on Application of Accelerators in Research and Industry, October 10-15, 2004, Fort Worth, Texas, LLNL.

27. L. Wielopolski, M. Todosow, J. Jones, "CERBERUS: A triple-pronged system for inspecting cargo containers for IND, SNM, and explosives", Active Interrogation Workshop, 28- 29 June, 2004, Idaho Falls, ID.

28. B. J. Micklich, D. L. Smith, T. N. Massey, C. L. Fink, D. Ingram, "FIGARO: detecting nuclear materials using high-energy gamma-rays", Nuc. Inst. Meth. A 505, 466-469 (2003).

29. S. Fetter, V. A. Frolov, M. Miller, R. Mozley, O. F. Prilutsky, S. N. Rodionov, R. Z. Sagdeev, "Detecting nuclear warheads", Science \& Global Security, 1, 1990, pp. 225302.

30. G. R. Keepin, "Nuclear safeguards research and development ", Los Alamos National Laboratory, LA-4368-MS, October-December, 1969.

31. D. Slaughter, M. Accatino, A. Bernstein, J. Candy, A. Dougan, J. Hall, A. Loshak, D. Manatt, A. Meyer, B. Pohl, S. Prussin, R. Walling, D. Weirup, "Detection of special nuclear material in cargo containers using neutron interrogation ", Lawrence Livermore National Laboratory, UCRL-ID-155315, August, 2003.

32. C. E. Moss, C. A. Goulding, C. L. Hollas, W. L. Myers, "Linear accelerator-based active interrogation for detection of highly enriched uranium", Conference on Accelerator Applications in Research and Industry, 12 November, 2002, Denton, TX.

33. J. L. Jones, "Proof of concept assessment of a photofission based interrogation system for the detection of shielded nuclear material ", Idaho National Engineering Laboratory, INEEL/EXT-1523, November, 2000.

34. J. L. Jones, "Detection of pulsed bremsstrahlung-induced, prompt neutron capture gamma- rays with a HPGe detector", SPIE International Conference on Neutrons in Research and Industry, 2867, 202, June, 1996, Crete, Greece.

35. W. Bertozzi, R. Ledouk, "Nuclear Resonance Fluorescense Imaging in Non-Intrusive Cargo Inspection" MIT and Passport Systems, Inc., CAARI $200418^{\text {th }}$ International conference on Application of Accelerators in Research and Industry, October 10-15, 2004, Fort Worth, Texas. 